附記：本突聒を柤当したのは首所吉野久雄技官である。

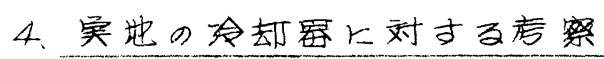

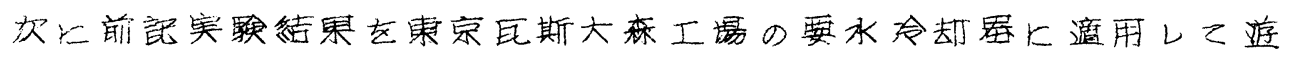

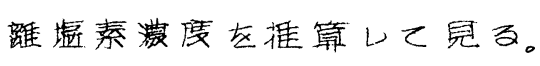

要水冷缩悬の請保件:

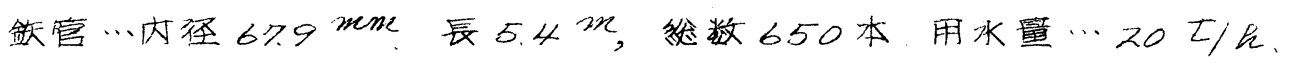
管内流速…14 $14 /$ min 通雷…3 $30 \times 4=120 \mathrm{~A}$

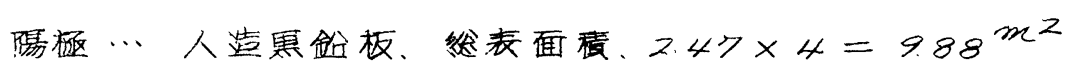

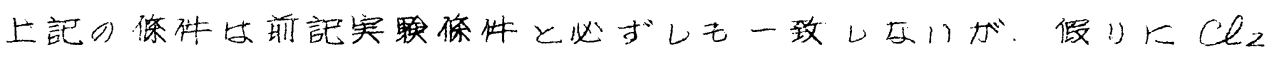

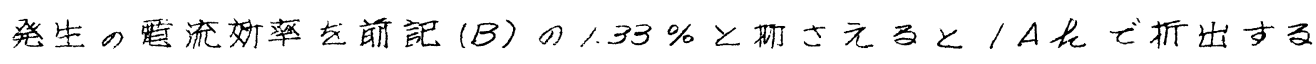
Clzdノ323gであるから.

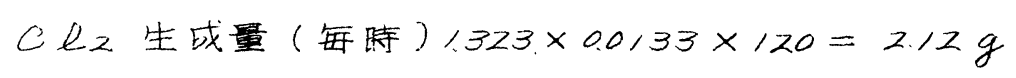

川まニのCl.が全部冷却海水上溶解するとして

$C l$ 工最大满度 $=.212 \mathrm{~g} / 20 \mathrm{t}=0.106 \mathrm{PP}$ m

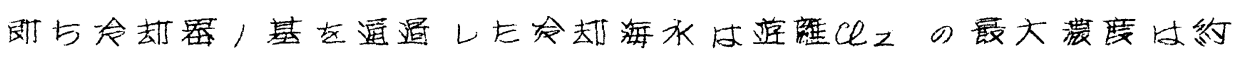

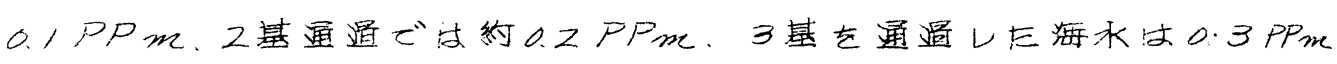

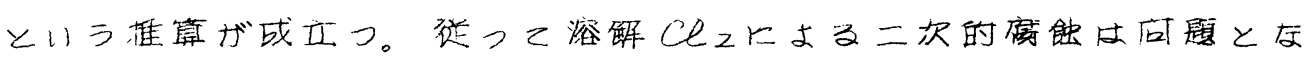

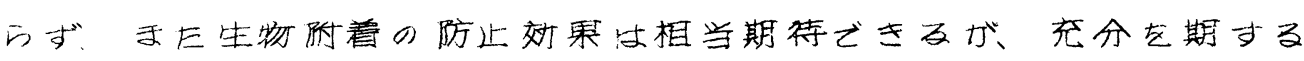

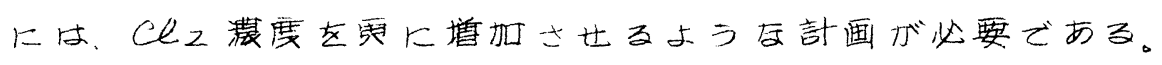

\title{
人孔䟧水の化学処理による ケーブル㰸被の防蝕
}

山口期忠。新田正雄

\section{1. 綾 言}

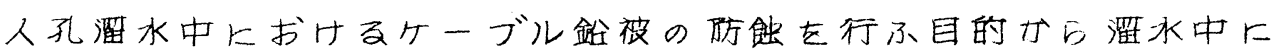
芒硝（水硫酸ソーダNazSO凶）を投入することによって、との化 学処理を行ひ、鉛被の隄㮀部面上不溶性の被膜を形成して不伤態

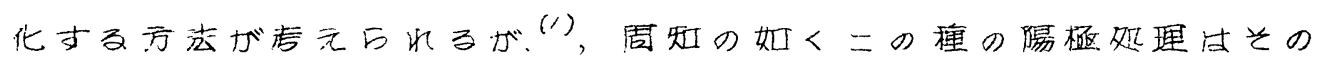




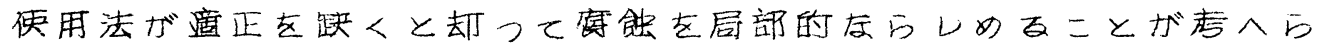

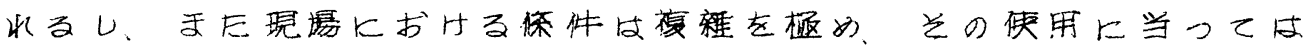

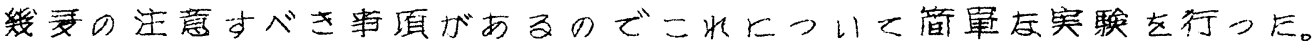
2. 实駼の结果

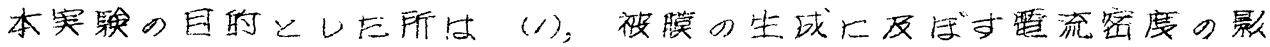

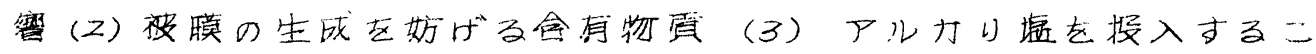

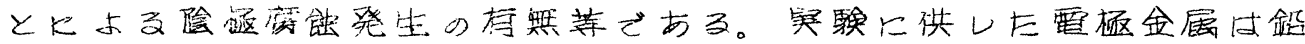

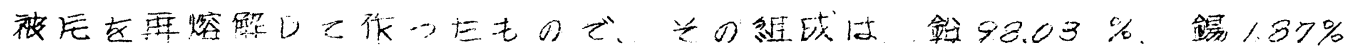

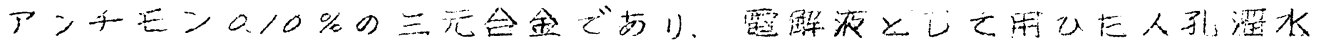

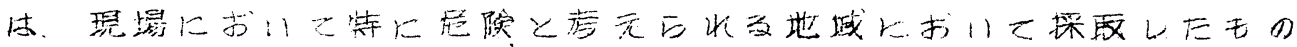

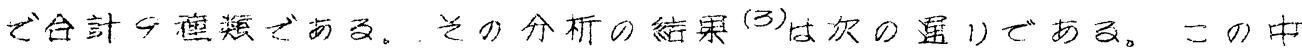

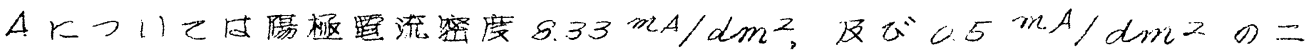

\begin{tabular}{|c|c|c|c|c|}
\hline 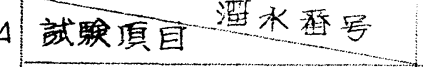 & No.' & No: z & No. 3 & No. 4 \\
\hline (1) $P_{H}$ & 7.0 & 6.7 & 8.1 & 7.4 \\
\hline (2) 垔薄 $\left(a t .25^{\circ} \mathrm{C}\right)$ & $1.62 \times 10^{-4}$ & $2.34 \times 10^{-4}$ & $652 \times 10^{-4}$ & $653 \times 10^{-4}$ \\
\hline (3) 寀在酸委 $m \log L^{-!}$ & 63 & 41 & 9.1 & 33 \\
\hline 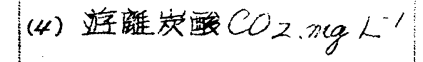 & 7.1 & 190 & - & 129 \\
\hline 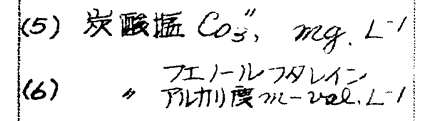 & $\longrightarrow$ & - & $\begin{array}{l}5.1 \\
0.17\end{array}$ & - \\
\hline 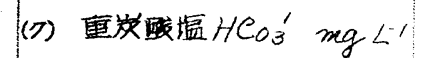 & 647 & 83.6 & .06 .1 & 2611 \\
\hline 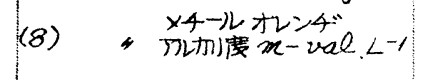 & 1.06 & 137 & 1.74 & 428 \\
\hline 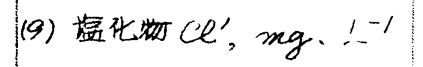 & 63 & 10.5 & 63.9 & 49.4 \\
\hline (10) オUシシ & 243 & 28.3 & 55.8 & 628 \\
\hline (11) KMnO4 消管量 $m g$ & - & -.. & 0.4 & 0.8 \\
\hline (uz) 硫酸境 $S 0_{u}^{\prime \prime}, \mathrm{mg} \cdot \mathrm{L}^{-1}$ & 9 & 12 & 25 & 15 \\
\hline (B) PVE $=P \mathrm{NH} / 3, \mathrm{mg} L^{-1}$ & - & + & - & - \\
\hline 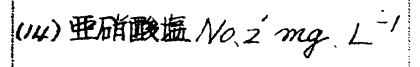 & 土 & \pm & \pm & \pm \\
\hline (15) 磷酸 垭 No.3, $2 \mathrm{~kg} . \mathrm{L}^{-1}$ & H & H & H & H \\
\hline
\end{tabular}




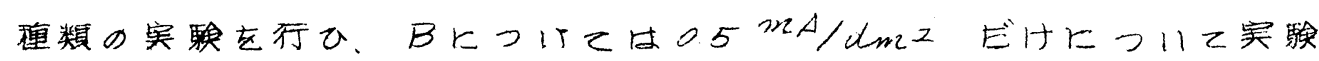

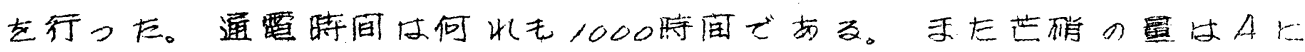

\begin{tabular}{|c|c|c|c|c|c|}
\hline 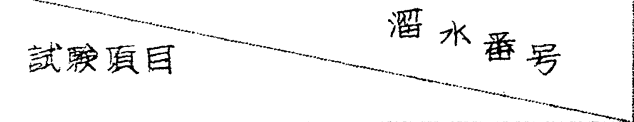 & $\left.\begin{array}{l}\text { No.1 } \\
\text { Hand } \\
\text { Hole }\end{array}\right)$ & $\left.\begin{array}{c}\text { No } 2 \\
\text { Man } \\
\text { hole }\end{array}\right)$ & $\begin{array}{l}\text { No.3 } \\
\left(\begin{array}{c}\text { Man } \\
\text { hole }\end{array}\right)\end{array}$ & $\begin{array}{c}\text { No.4 } \\
\left(\begin{array}{c}\text { Man } \\
\text { hole }\end{array}\right)\end{array}$ & $\begin{array}{l}\text { No.5 } \\
\text { (地下水) }\end{array}$ \\
\hline (1) PH & 7. & 65 & $7 /$ & 67 & 69 \\
\hline (2) 此柢抗 $25^{\circ} \mathrm{C} \quad 2-\mathrm{Cun}$ & 365 & 1530 & 1870 & 1780 & 1390 \\
\hline (3) 龤 $\begin{aligned} P_{6} \cdot & \gamma L^{-1} \\
& (\gamma=0.00 / \mathrm{mg})\end{aligned}$ & 41 & 165 & 31 & 25 & - \\
\hline (4) 㴤在酸 $O_{z}, m g .<-1$ & 3.69 & 107 & 063 & 185 & 309 \\
\hline 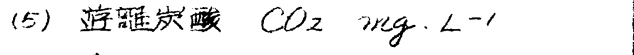 & 45.3 & 45.1 & 18.1 & 48.1 & 604 \\
\hline 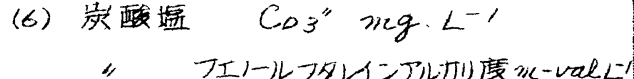 & 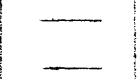 & - & - & - & - \\
\hline (7) 重岩酸演 $\mathrm{HCO}_{3}^{\prime} m g . \mathrm{L}^{-1}$ & $43 \pi 2$ & 2635 & 215.0 & 2647 & 261,1 \\
\hline 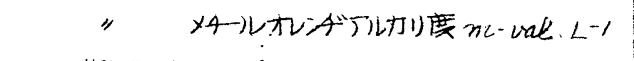 & 7.99 & 4.32 & 352 & 434 & 428 \\
\hline 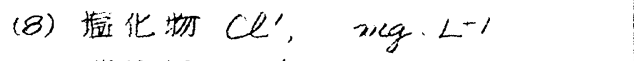 & ルクフ & 58.8 & 484 & 42.9 & 41.9 \\
\hline (9) 硝酸境 $\mathrm{NO}_{3}^{\prime}, \quad m \mathrm{mg} . \mathrm{Ll}^{\prime}$ & + & - & - & - & \pm \\
\hline 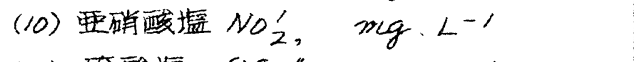 & H & $士$ & \pm & H & - \\
\hline (11) 硫酸挜 50 4", $\operatorname{reg} .<-1$ & 380 & 26 & Z/ & 19 & 84 \\
\hline 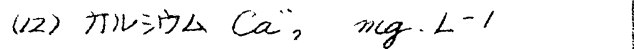 & 376.4 & 65.8 & 49.6 & 65.7 & 57.9 \\
\hline 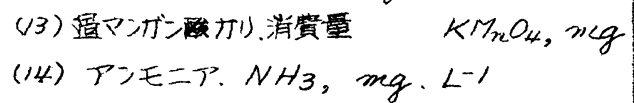 & $\begin{array}{c}52.8 \\
+\end{array}$ & $\begin{array}{l}12.7 \\
+1\end{array}$ & $\begin{array}{l}92 \\
+1\end{array}$ & $\begin{array}{l}109 \\
+1\end{array}$ & $\begin{array}{l}6.6 \\
+\end{array}$ \\
\hline
\end{tabular}

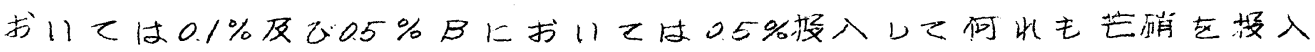
しをい場合の結果と比晈した。结果はすべて重㻎减を测定すること

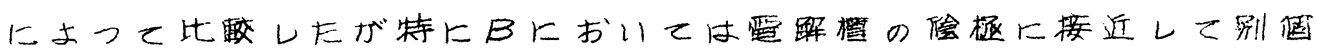

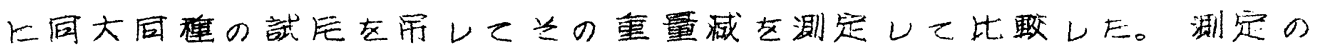

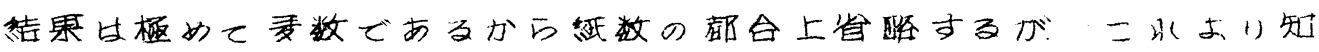
られる事填について次上述べることにする。

3. 结果の察

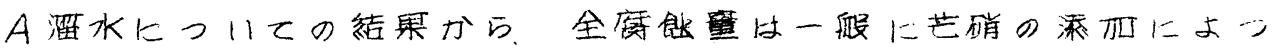

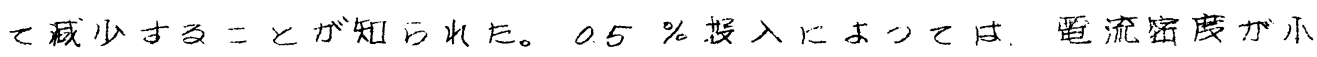

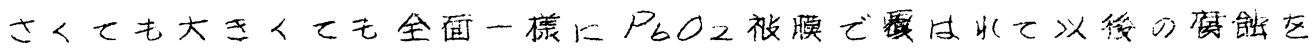

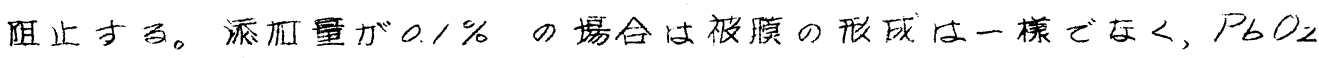

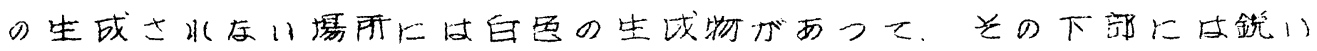




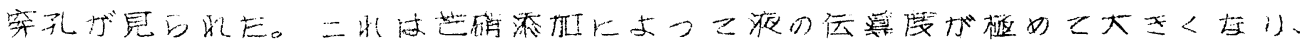

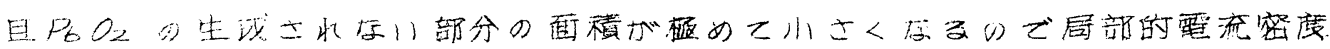

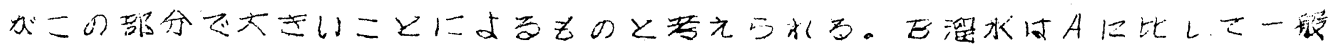

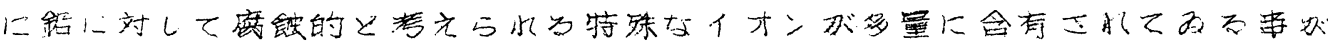

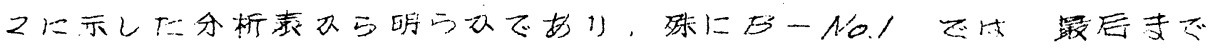

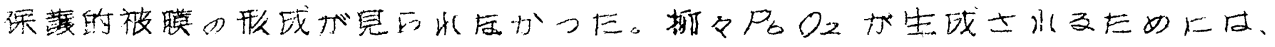

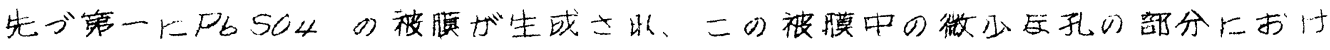

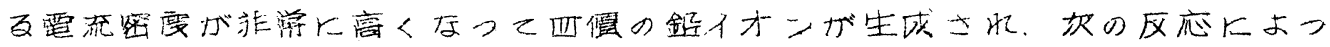

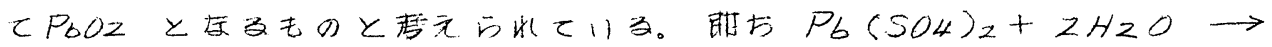

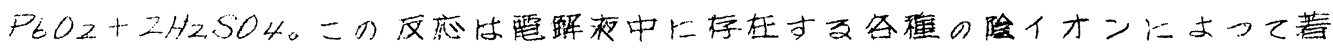

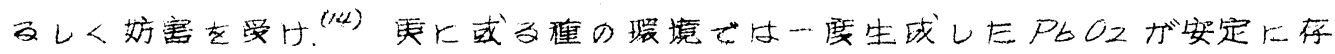

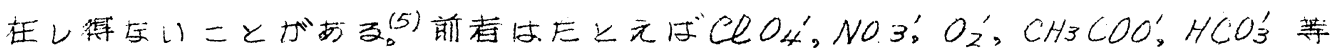

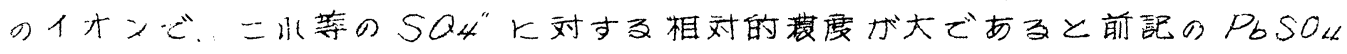

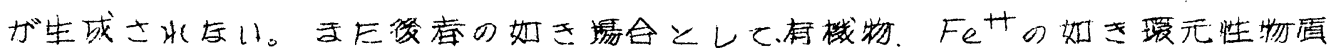

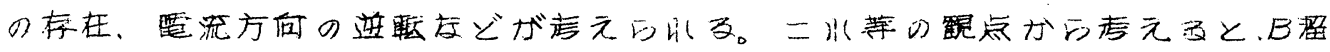

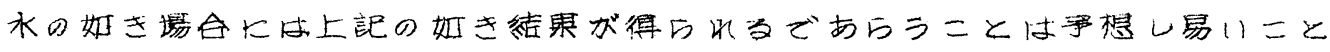

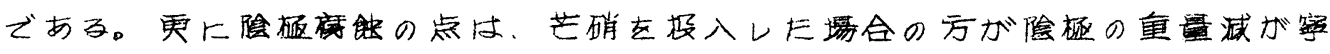

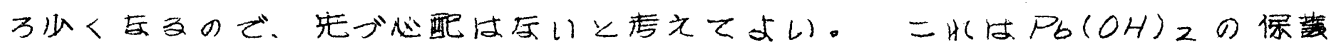

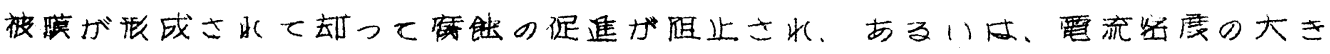

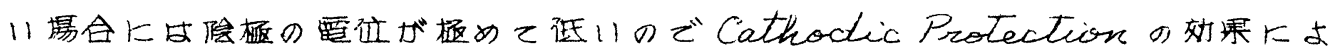
るものと充の山る。

4. 结言

3に速べたニとから明かなように、本方法によつて完全を防能效果を得る

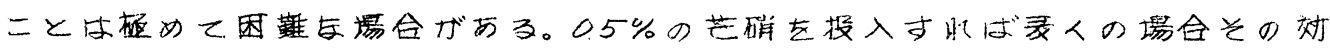

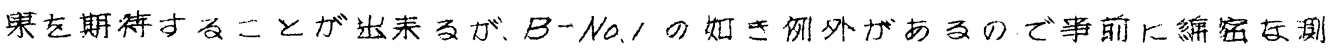

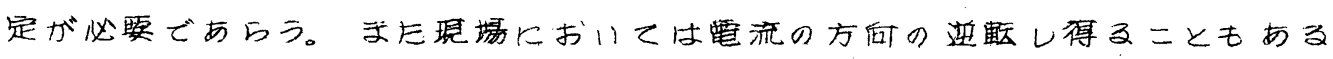

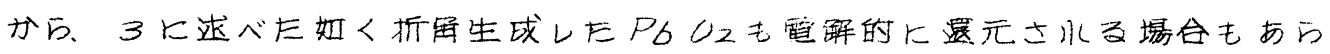

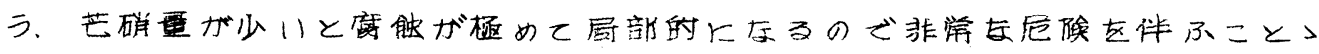

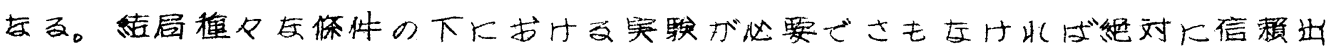

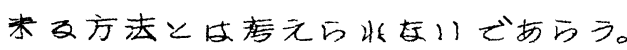

弜用文献

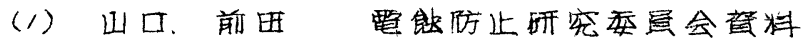

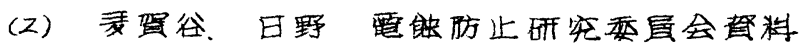

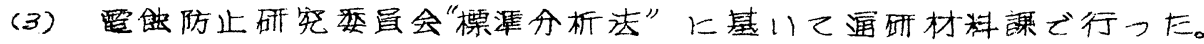

(7) Allmand and Ellinghan. Applied Electro-Chemistry. 2 nd Edd. (1924)

(5) F.Sandmeier Wie erkennt man Art und Ursache der Schüden an Bleikebe en? (1946) 